\title{
Owner reports of attention, activity, and impulsivity in dogs: a replication study
}

Lisa Lit ${ }^{1,2^{*}}$, Julie B Schweitzer ${ }^{2}$, Ana-Maria losif ${ }^{3}$, Anita M Oberbauer ${ }^{4}$

\begin{abstract}
Background: When developing behaviour measurement tools that use third party assessments, such as parent report, it is important to demonstrate reliability of resulting scales through replication using novel cohorts. The domestic dog has been suggested as a model to investigate normal variation in attention, hyperactivity, and impulsive behaviours impaired in Attention Deficit Hyperactive Disorder (ADHD). The human ADHD Rating Scale, modified for dogs and using owner-directed surveys, was applied in a European sample. We asked whether findings would be replicated utilizing an Internet survey in a novel sample, where unassisted survey completion, participant attitudes and breeds might affect previous findings.

Methods: Using a slightly modified version of the prior survey, we collected responses $(n=1030,118$ breeds representing 7 breed groups) primarily in the United States and Canada. This study was conducted using an Internet survey mechanism.

Results: Reliability analyses confirmed two scales previously identified for dogs (inattention [IA], hyperactivityimpulsivity $[H A-I M]$ ). Models including age, training status, and breed group accounted for very little variance in subscales, with no effect of gender.

Conclusions: The factor invariance demonstrated in these findings confirms that owner report, using this modified human questionnaire, provides dog scores according to "inattention" and "hyperactivity-impulsivity" axes. Further characterization of naturally occurring variability of attention, activity, and impulsivity in domestic dogs may provide insight into genetic backgrounds underlying behaviours impaired in attention and associated disorders.
\end{abstract}

\section{Background}

Attention deficit hyperactivity disorder (ADHD), a neurodevelopmental disorder characterized by inattention, hyperactivity, and impulsivity, has a prevalence rate of $3-7 \%$ in children [1] and over $4 \%$ in adults [2]. The disorder, diagnosed primarily through parent and teacher report, is associated with impaired social relationships and academic functioning, as well as increased substance abuse, risk-taking behaviour, and underemployment [3]. Though twin concordance studies support high heritability, global susceptibility genes have not been identified, and non-overlapping genetic studies implicate multiple genes and encompass multiple chromosomal regions [[4], e.g. [5], reviewed in [6]].

An appropriate animal model for ADHD must demonstrate face (similar behavioural characteristics),

\footnotetext{
* Correspondence: llit@ucdavis.edu

${ }^{1}$ MIND Institute and Department of Neurology, University of California at
} Davis, Sacramento, CA, USA construct (theoretical rationale), and predictive (correctly predict behavioural and biological characteristics) validity [7]. More specific criteria described for face validity of animal models for ADHD include impulsivity that develops over time, inattention with temporally widely-spaced stimuli, and hyperactivity in a non-novel environment that develops over time; ADHD-specific criteria for construct validity include altered reinforcement of novel behaviour and deficient extinction of previously reinforced behaviour [7].

Although non-human primates exposed to the dopamine neurotoxin 1-methyl-4-phenyl-1,2,3,6-tetrahydropyridine (MPTP) have been suggested as appropriate ADHD models [8-10], animal models for ADHD have historically been rat or mouse models [11]. Rodent models offer advantages of genetic homogeneity, relatively low cost, ease of generating and maintaining large populations for research, and control of environmental 
variables [11]. An additional advantage is a simpler nervous system offering similar basic behavioural mechanisms.

The spontaneously hypertensive rat (SHR), a rodent model demonstrating face, construct and predictive validity for ADHD, displays inattentive, hyperactive and impulsive behaviours [12]. These ADHD-like behaviours are genetic rather than environmental, as demonstrated by lack of effects of cross-fostering [13] or social isolation [14]. The SHR also demonstrates some sex differences similar to those observed in ADHD in humans [15]. There have been reports questioning the validity of the SHR, particularly when compared with the WistarKyoto (WKY) strain typically used as a control [16-18]. However, further investigations have demonstrated that distinct strains are more representative of different subtypes of ADHD, and that insufficient consideration of substrain variability together with paradigm application might underlie concerns about SHR validity as an ADHD model [[19], reviewed in [20]].

Additional rodent models for ADHD have been created by genetic engineering to generate an ADHD-like phenotype, such as the SNAP-25 deficient mouse mutant coloboma [[21-23], reviewed in [24]] and the dopamine transporter knockout mouse (DAT-KO) [e.g. $[25,26]]$. Other models have been developed through experimental exposure to central nervous system insult during prenatal or postnatal development, for example the anoxic mouse $[27,28]$, rearing in social isolation [29], and exposure to environmental toxins such as polychlorinated biphenyls and lead [30,31]. Unlike the SHR, these models do not recapitulate all symptoms of ADHD and thus fail to meet criteria for validity as previously described [7]. Despite this, some overlap has been found across models; for example, overlaps in neurotransmitter-related and epigenetic gene expression levels were recently identified in both SHR and PCBexposed Sprague-Dawley rats [32]. Therefore these additional models might offer complementary information to help tease apart the behavioural and biological heterogeneity found in ADHD.

Recently, the domestic dog has been proposed as an innovative genetic and behavioural model for complex behaviours in humans [33-37], including ADHD [38-40]. The dog model has the potential to provide an important additional animal model in the quest to understand ADHD, supplementing rather than replacing existing animal models. Genetically, the dog is less diverged from the human than the mouse [41], with dogs and humans having approximately the same number of genes, most of which descended from the same ancestral genes [34]. Behaviourally, dogs demonstrate heritable social cognitive behaviours in response to both conspecific and human cues [reviewed in [42]], often exceeding capabilities of non-human primates $[43,44]$. The predictive validity of a dog model is further enhanced by observed effects of human psychopharmacological agents used in dogs for behaviours phenotypically similar to those seen in human psychopathologies, such as obsessive-compulsive disorder and generalized anxiety disorder [45]. This suggests that similar underlying biological mechanisms contribute to homologous behaviours across dogs and humans.

Modified human measurement scales have been applied successfully to evaluate dog behaviours [e.g. [46]], including behaviours relevant to ADHD. The Du Paul ADHD-Rating Scale (ADHD-RS) [47] is based on the DSM-IV criteria for ADHD and is composed of two subscales, inattention and hyperactivity/impulsivity. This scale, modified for dogs and using owner-directed surveys, was recently validated using Eastern European dog owners [40]. Although pathological levels of inattention, hyperactivity or impulsivity have not been established in dogs, these scales may be useful for examining genetic contributions to variability of the represented behaviours in dogs. For example, subscales have subsequently been used to consider the association between polymorphisms in genes that have been implicated in human ADHD and variation in subscale scores in dogs [38,39].

However, because parent report measures in humans can be subject to bias based on many factors, such as cultural background $[48,49]$, it is possible that survey findings of Vas et al. [40] might be influenced by regional beliefs about dog behaviour, training practices, and preferred dog breeds. In addition, the previous surveys were completed with researcher assistance if necessary [40]. Thus, we questioned whether comparable findings could be obtained using a novel population of dog owners, in the absence of researcher assistance to complete the survey.

Our study does not address the question of whether dogs with extreme scores display evidence of a medical or behavioural problem $[50,51]$, or whether the dog is an appropriate animal model for pathologies reflected in ADHD based on this questionnaire [50,52]. The primary purpose of this study is to expand the findings in Vas et al. [40] by utilizing an unassisted Internet survey targeting dog owners, to investigate whether different beliefs about dog behaviour, breeds represented, and training practices might result in markedly different response profiles than those in the original Eastern European sample. Similar findings would underscore the reliability of owner report for these behaviours in their dogs, as well as validate Internet survey data collection for observed attention, activity, and impulsivity related behaviours of the dog. 


\section{Methods}

\section{Dog-ADHD rating scale}

A modification of the dog-ADHD rating scale owner version used by Vas et al. [40] was used (Additional file 1 ). The question "It is excessive, difficult to control, if it lunges it is hard to hold back." was removed as pilot studies suggested that this question was highly dependent on training and equipment. Specifically, the increased utilization of training equipment that typically offers immediate control over the behaviours described in this question (i.e., dog halters, no-pull harnesses) might substantially skew responses. Other questions were modified slightly to adjust for language differences. A 5-point Likert scale was used instead of a 4-point Likert scale (response choices were "Never/Rarely," "Occasionally," "Often," "Very Frequently," and "Always," scored as $0,1,2,3$, and 4 respectively). However, overall the revised rating scale in this report remained reflective of the ADHD Rating Scale, Parent version [47], with questions limited to those appropriate for dog behaviours. As in Vas et al. [40], two a priori subscales were initially defined: an inattention subscale (IA, questions 1, $2,3,7,9,11)$ and a hyperactivity-impulsivity subscale (HA-IM, questions 4, 5, 6, 8, 10, 12) (Additional file 1). The Institutional Review Board at the University of California at Davis approved the survey.

\section{Additional information}

Respondents were asked to provide geographical region of residence, dog's breed, gender, spay/neuter status, birth date, medications, and health problems. Training and certification status of dogs were also collected, including whether dogs had basic pet dog training, certification by the American Kennel Club (AKC) in canine manners (Canine Good Citizen, CGC), and training/certification in competitive obedience, schutzhund, agility, therapy dog, search and rescue, scent detection, or other venues.

\section{Survey completion}

The survey was completed via an Internet survey mechanism [53] (Additional file 1). A link to the survey was initially distributed via email to dog owners and groups provided by the authors, as well as posted on several dog-related training and pet groups. To avoid an inherent selection bias in those exposed to the survey, efforts were made to target pet, sport, and professional dog owners and handlers. Pilot studies indicated that survey completion took between 5 and 10 minutes. Survey data were collected between September 2008 and January 2009.

\section{Participants}

Sample demographics are summarized in Table 1. Initial survey responses included 1184 dogs. Dogs were excluded $(n=46)$ if age data or training background data were missing, or if dog age was greater than 203 months. The age cutoff of 203 months includes dogs less than 17 years of age at the time the owner completed the survey. Specifically, seven dogs were omitted using this criterion. Of these, three were also missing data, and were excluded on that basis. Ages of remaining dogs ranged from 19 to 43, appeared as an extreme tail in the distribution of dog ages, potentially represented erroneous responses, and were eliminated. Samples with missing responses on the ADHD Rating Scale survey were also excluded $(n=108)$, yielding a final analysis sample of 1030 dogs. Responses were received predominantly from the United States $(n=980)$ and from Canada $(n=41)$. Responses were also received from Australia, England, Germany, New Zealand, Portugal, and Scotland ( $n=9$ total) (Table 1 ). Because these nine responses represented countries not included in Vas et al. [40], they were retained for analysis. Mean age in months $( \pm$ SEM $)$ of all dogs included $(n=1030)$ was $75.8 \pm 1.4$ months.

Based on owner report of dog breeds, 118 AKC-recognized breeds were represented (Additional file 2). These were further stratified according to AKC group (Herding, Hound, Non-sporting, Sporting, Terrier, Toy, and Working) (Table 1). Additionally, 51 dogs were nonAKC recognized purebreds, and 205 dogs were mixedbreed.

To assign Training Status, dogs with only pet dog training and/or training for a CGC title were considered "Untrained", dogs with either a CGC title or training in a working discipline were defined as "Beginner", and dogs with at least one title in a working discipline were considered to have "Advanced" training (Table 1).

\section{Statistical analyses}

Analyses were based on those performed by Vas et al [40]. IA and HA-IM subscale scores were calculated for each dog by adding scores for questions within each subscale. Cronbach's alpha was used to examine reliabilities of a priori subscale assumptions [54,55]. Independence of subscales was evaluated with Pearson correlations. Factor analysis using varimax rotation was used on all dog-ADHD survey questions to identify factors and loadings of individual items, with results compared to a priori subscale definitions.

Effects of Age, Neuter Status, Gender, Breed Group, and Training Status on subscale scores were evaluated with analysis of variance (ANOVA) or covariance (ANCOVA) models, as appropriate. Bonferroni corrections were used in pairwise comparisons to adjust for multiple comparisons.

Significance of predictors was assessed using two-sided tests with $\alpha=0.05$. SPSS 17.0 was used for all analyses [56]. 
Table 1 Sample demographics, $n=1030$ dogs.

\begin{tabular}{|c|c|c|}
\hline Age groups & $n$ & $($ mean $\pm S E)$ \\
\hline Mean age, all dogs & 1030 & $(75.8 \pm 1.4)$ \\
\hline Juvenile (4.5-23 months) & 129 & $(15.6 \pm 0.5)$ \\
\hline Young Adult (24-59 months) & 301 & $(42.7 \pm 0.6)$ \\
\hline Adult (60-95 months) & 260 & $(77.1 \pm 0.6)$ \\
\hline Senior (96-23 months) & 340 & $(126.9 \pm 1.3)$ \\
\hline \multicolumn{2}{|l|}{ Geographic distribution of responses } & $(\%)$ \\
\hline $\begin{array}{l}\text { (49) US states represented (incl. } \\
\text { District of Columbia) }\end{array}$ & 980 & $(95.15)$ \\
\hline Canada & 41 & (3.98) \\
\hline (7) Countries other than United States & 9 & $(0.87)$ \\
\hline \multicolumn{3}{|l|}{ Gender distributions } \\
\hline Males & 531 & $(51.6)$ \\
\hline Neutered males & 392 & $(38.1)$ \\
\hline Intact males & 139 & $(13.5)$ \\
\hline Females & 495 & $(48.1)$ \\
\hline Spayed females & 408 & (39.6) \\
\hline Intact females & 87 & $(8.4)$ \\
\hline \multicolumn{3}{|l|}{ Breed information } \\
\hline Number of AKC breeds represented & 118 & \\
\hline \multicolumn{3}{|l|}{ Distribution of dogs by AKC group } \\
\hline Herding & 260 & $(25.2)$ \\
\hline Hound & 51 & (5.0) \\
\hline Non-sporting & 85 & (8.3) \\
\hline Sporting & 205 & (19.9) \\
\hline Terrier & 56 & (5.4) \\
\hline Toy & 37 & (3.6) \\
\hline Working & 70 & (6.8) \\
\hline Not AKC & 51 & (5.0) \\
\hline Mixed breed & 205 & (19.9) \\
\hline \multicolumn{3}{|l|}{ Training status } \\
\hline Untrained & 288 & $(28.0)$ \\
\hline Beginner & 289 & $(28.1)$ \\
\hline Advanced & 453 & $(44.0)$ \\
\hline
\end{tabular}

${ }^{1}$ Note: age was used as a continuous covariate in analyses. As such, Age Groups are provided for informational purposes only.

\section{Results}

\section{Reliability of a priori subscales}

The $a$ priori IA subscale with six questions (questions 1, $2,3,7,9,11$, Additional file 1) had good internal reliability, $\alpha=0.88$. All items appeared worthy of retention, as Cronbach's alpha would not measurably improve with exclusion of any item (Table 2, "Cronbach's alpha if item deleted" column). All items correlated with the total subscale to a good degree (lower $r=0.42$ ) (Table 2, "Corrected item-Total Correlation" column).

The a priori hyperactivity-impulsivity subscale (HAIM) with six questions (questions $4,5,6,8,10,12$, Additional file 1) had lower internal reliability, $\alpha=0.67$. As with the IA subscale, there would be very little improvement with exclusion of any item for the HA-IM subscale (Table 2, "Cronbach's alpha if item deleted" column). There was lower correlation of individual items with the total subscale (lower $r=0.26$ ). Overall, the reliability analysis of the HA-IM scale $(\alpha<0.7)$ suggested the possible existence of additional subscales within that scale [57].

\section{Factor analysis}

To explore dimensionality of scale items and whether additional constructs could account for patterns of item scores, factor analysis with varimax rotation was performed using all 12 questions in the dog ADHD rating scale as input (Additional file 1). Using the criterion of eigenvalues greater than $1.0[58,59]$, three factors, identified as Inattention (IA, $\mathrm{M}=0.19, \mathrm{SE}=0.004$, range $=$ 0.00-0.62), Hyperactivity-Impulsivity 1 (HY1, $\mathrm{M}=0.18$, $\mathrm{SE}=0.004$, range $=0.00-0.70)$, and Hyperactivity-Impulsivity 2 (HY2, $\mathrm{M}=0.36, \mathrm{SE}=0.004$, range $=0.14-0.70)$, were extracted accounting for $59.2 \%$ of the total variance (Table 3).

The first factor, IA (eigenvalue $=4.57$ ), included the six questions comprising the a priori inattention subscale and accounted for $38.1 \%$ of total variance. The second factor, HY1 (eigenvalue = 1.51), accounted for $12.6 \%$ of total variance and included four of the six questions represented in the HA-IM scale. The remaining two questions from the a priori HA-IM scale are found in factor three, HY2 (eigenvalue $=1.02$ ), accounting for $8.5 \%$ of total variance. These two questions (question 8 and question 10, Additional file 1) had high loadings on this factor ( 0.82 and 0.69 respectively). In addition, question 6 loaded across both the second (0.54) and third (0.53) factors, and subsequently was included in the calculation of both subscales. Thus, the a priori HA-IM scale was split, so that questions 4, 5, 6, and 12 comprised the Hyperactivity-Impulsivity scale 1 (HY1), and questions 6,8 , and 10 were used to create a Hyperactivity-Impulsivity scale 2 (HY2) (Additional file 3).

We then compared the a priori subscale scores for inattention and hyperactivity/impulsivity (described above) with factor scores generated through factor analysis. As expected, subscale scores and factor scores were significantly and highly correlated (IA-Factor 1: $r=$ 0.95, HY1-Factor 2: $r=0.83$, HY2-Factor 3: $r=0.94$, all $p$ values $<0.0001)$. As found in Vas et al. [40], the strong relationships between a priori subscale scores and factor scores suggest that Factor 1 is associated with attention and that Factors 2 and 3 are related to activity and impulsive behaviours.

Finally, because both IA and HY1 subscales demonstrated slight positive skew and kurtosis, a logarithmic transformation was applied. To allow comparison across subscales, the logarithmic transformation was also applied to the HY2 subscale. Means and standard deviations for transformed subscales were: IA $0.20 \pm 0.14$, 
Table 2 For each a priori subscale, Cronbach's alpha and subscale component reliabilities.

\begin{tabular}{|c|c|c|c|c|}
\hline & Mean & $\begin{array}{l}\text { Standard } \\
\text { Deviation }\end{array}$ & $\begin{array}{r}\text { Corrected item - Total } \\
\text { Correlation } \\
\end{array}$ & $\begin{array}{r}\text { Cronbach's alpha if item } \\
\text { deleted }\end{array}$ \\
\hline \multicolumn{5}{|l|}{ Inattention subscale (alpha $=0.85)$} \\
\hline 1. Other things attract attention & 1.81 & 0.81 & 0.73 & 0.80 \\
\hline 2. Loses interest easily & 1.79 & 0.80 & 0.67 & 0.82 \\
\hline 3. Difficulty concentrating & 1.48 & 0.70 & 0.71 & 0.81 \\
\hline $\begin{array}{l}\text { 7. Doesn't pay attention to someone speaking to } \\
\text { him/her }\end{array}$ & 1.40 & 0.71 & 0.42 & 0.86 \\
\hline 9. Difficulty performing practiced tasks & 1.41 & 0.68 & 0.58 & 0.83 \\
\hline 11. Easily distracted & 2.02 & 0.88 & 0.70 & 0.81 \\
\hline \multicolumn{5}{|l|}{ Hyperactivity-Impulsivity subscale (alpha $=0.67$ ) } \\
\hline 4. Difficulty maintaining stay & 1.91 & 0.89 & 0.36 & 0.63 \\
\hline 5. Barks endlessly & 1.36 & 0.75 & 0.30 & 0.66 \\
\hline 6. Fidgets or in constant motion & 1.54 & 0.95 & 0.52 & 0.58 \\
\hline 8. Likes active play/running around & 3.59 & 1.23 & 0.26 & 0.69 \\
\hline 10. Reacts hastily/anticipates & 2.15 & 1.00 & 0.48 & 0.59 \\
\hline 12. Cannot wait & 1.55 & 0.81 & 0.54 & 0.58 \\
\hline
\end{tabular}

HY1 $0.18 \pm 0.14$, and HY2 $0.36 \pm 0.14$. As expected from loading patterns, subscales were not independent. IA was correlated with both HY1 $(r=0.51, p<0.001)$ and HY2 $(r=0.24, p<0.001)$, and HY1 and HY2 were correlated $(r=0.51, p<0.001)$.

\section{Age}

Age in months was calculated based on birth dates provided for dogs. There was an association between Age in months and Training Status $(r=0.14, p<0.0001)$, with older dogs more likely to have more training.

Additionally, Age in months was a significant predictor of IA, HY1, and HY2 (all $p$ values < 0.001); older dogs had lower subscale scores. Although Age accounted for very little variance in each subscale $\left(R^{2}\right.$ IA: 0.02, HY1: 0.02, HY2: 0.08), it was included as a covariate in subsequent analyses.

\section{Univariate analyses}

Univariate ANCOVAs controlling for Age were performed to assess the effect of each qualitative demographic independent variable (Gender, Neuter Status, Breed Group, and Training Status) on subscales.

Effects of Gender and Neuter Status were evaluated using a $2 \times 2$ (Gender [Male, Female] $\times$ Neuter Status [Neutered, Intact]) factorial ANCOVA. There was a main effect of Gender on HY1 $\left(p=0.02, \eta^{2}=0.01\right)$; females had higher mean HY1 scores than males (Table 4). There was a very small but significant main effect of Neuter Status on IA $\left(p=0.03, \eta^{2}=0.005\right)$, with neutered $\operatorname{dogs}(M=0.20, \mathrm{SE}=0.01)$ having higher IA scores than Intact dogs (Table 4). There was no interaction between Gender and Neuter Status.

There were differences in both IA and HY1 subscales according to Training Status (IA: $p<0.001, \eta_{p}{ }^{2}=0.049$,

Table 3 Principal component analysis (varimax rotation) factor loadings.

\begin{tabular}{lrrr}
\hline & \multicolumn{2}{c}{ Subscale } \\
\hline & Inattention & Hyperactivity-Impulsivity 1 & Hyperactivity-Impulsivity 2 \\
\hline 1. Other things attract attention & 0.819 & 0.098 & 0.198 \\
2. Loses interest easily & 0.831 & 0.036 & -0.009 \\
3. Difficulty concentrating & 0.784 & 0.357 & -0.025 \\
7. Doesn't pay attention to someone speaking to him/her & 0.451 & 0.382 & 0.111 \\
9. Difficulty performing practiced tasks & 0.596 & 0.147 & 0.099 \\
11. Easily distracted & 0.774 & 0.484 & 0.300 \\
4. Difficulty maintaining stay & 0.387 & 0.801 & 0.147 \\
5. Barks endlessly & 0.072 & 0.543 & -0.030 \\
6. Fidgets or in constant motion & 0.074 & 0.554 & 0.530 \\
12. Cannot wait & 0.378 & -0.093 & 0.344 \\
8. Likes active play/running around & -0.046 & 0.207 & 0.820 \\
10. Reacts hastily/anticipates & 0.213 & & 0.689 \\
\hline
\end{tabular}


Table 4 Raw means and standard errors (SE) for Breed Group, Training Status, Gender, and Neuter Status.

\begin{tabular}{|c|c|c|c|}
\hline & Inattention & Hyperactivity-Impulsivity 1 & Hyperactivity-Impulsivity 2 \\
\hline & Mean (SE) & Mean (SE) & Mean (SE) \\
\hline \multicolumn{4}{|l|}{ Breed Group } \\
\hline Herding & $1.51(0.03)$ & $1.57(0.04)$ & $2.58(0.05)$ \\
\hline Hound & $1.98(0.10)$ & $1.88(0.11)$ & $2.39(0.11)$ \\
\hline Non-sporting & $1.70(0.06)$ & $1.59(0.07)$ & $2.28(0.08)$ \\
\hline Sporting & $1.58(0.04)$ & $1.54(0.04)$ & $2.36(0.06)$ \\
\hline Terrier & $1.76(0.07)$ & $1.57(0.08)$ & $2.45(0.10)$ \\
\hline Toy & $1.84(0.11)$ & $1.71(0.12)$ & $2.22(0.15)$ \\
\hline Working & $1.58(0.14)$ & $1.46(0.07)$ & $2.32(0.08)$ \\
\hline Not AKC & $1.74(0.08)$ & $1.76(0.09)$ & $2.52(0.10)$ \\
\hline Mixed & $1.72(0.04)$ & $1.58(0.04)$ & $2.40(0.05)$ \\
\hline \multicolumn{4}{|l|}{ Training Status } \\
\hline Untrained & $1.82(0.04)$ & $1.80(0.04)$ & $2.37(0.05$ \\
\hline Beginner & $1.69(0.03)$ & $1.60(0.03)$ & $2.54(0.05)$ \\
\hline Advanced & $1.52(0.02)$ & $1.45(0.03)$ & $2.38(0.04)$ \\
\hline \multicolumn{4}{|l|}{ Gender } \\
\hline Female & $1.65(0.03)$ & $1.62(0.03)$ & $2.45(0.04)$ \\
\hline Male & $1.65(0.03)$ & $1.56(0.03)$ & $2.41(0.03)$ \\
\hline \multicolumn{4}{|l|}{ Neuter Status } \\
\hline Intact & $1.61(0.04)$ & $1.55(0.04)$ & $2.48(0.05)$ \\
\hline Spayed/Neutered & $1.66(0.02)$ & $1.60(0.02)$ & $2.41(0.03)$ \\
\hline
\end{tabular}

HY1: $p<0.001, \eta_{p}{ }^{2}=0.064$ ) (Table 4). Bonferroni corrected pairwise comparisons indicated that for both IA and HY1 subscales, Untrained dogs had higher mean scores than both Beginner and Advanced dogs (Table 4 ), and Beginner dogs had higher mean scores than Advanced dogs (Table 4).

There were significant differences in mean IA, HY1, and HY2 subscale scores (Table 4) according to Breed Group (IA: $p<0.001, \eta_{p}{ }^{2}=0.055$, HY1: $p=0.01, \eta_{p}{ }^{2}=$ 0.023 , HY2: $p=0.01, \eta_{p}{ }^{2}=0.022$ ). For IA, dogs in the Hound, Terrier, Toy, and Mixed Breed groups each had higher mean scores than dogs in the Herding group (Table 4). Dogs in the Hound group also had higher mean IA scores than dogs in the Sporting group (Table 4). For HY1 scores, dogs in the Hound group had higher mean HY1 scores than dogs in the Herding, Sporting, and Working groups (Table 4). However, for HY2, dogs in the Herding group had higher mean HY2 scores than dogs in the Non-sporting and Toy groups (Table 4).

\section{Adjusted analyses}

To evaluate contributions of Gender, Breed Group and Training Status predicting each of the three subscales, adjusted models were fitted for each subscale controlling for Age and using dog Gender, Training Status, and Breed Group as independent variables. Interactions between the predictors were also considered. Because the effect size of Neuter Status on IA was extremely small $\left(\eta^{2}=0.005\right)$, and inclusion would have reduced the power of the study, Neuter Status was not included in these analyses. Only terms that added significantly to the model were retained for each subscale. For the IA and HY1 subscales, there were main effects of Training Status (all $p$ values $<0.0001$ ) and Breed Group (IA: $p<$ 0.0001; HY1: $p=0.022$ ). For the HY2 subscale, there was only a main effect of Breed Group and the univariate model was retained. For all subscales, there was no effect of Gender when controlling for effects of Age.

Bonferroni-corrected pairwise comparisons for the IA and HY1 subscales using the model "Subscale score = (Age) $\times$ Training Status $\times$ Breed Group" showed that dogs in the Hound $(\mathrm{M}=0.29, \mathrm{SE}=0.02)$ group had higher mean IA scores than dogs in the Herding $(\mathrm{M}=$ $0.18, \mathrm{SE}=0.01)$ and Sporting $(\mathrm{M}=0.19, \mathrm{SE}=0.01)$ groups, and that Untrained $(\mathrm{M}=0.25, \mathrm{SE}=0.01)$ dogs had higher IA scores than Advanced $(\mathrm{M}=0.19, \mathrm{SE}=$ $0.01)$ dogs. This was different for HY1 scores; dogs in the Hound $(\mathrm{M}=0.22, \mathrm{SE}=0.01)$ group had higher mean HY1 scores than dogs in the Working $(M=0.15$, $\mathrm{SE}=0.02)$ group, and Untrained $(\mathrm{M}=0.24, \mathrm{SE}=0.01)$ dogs had higher mean HY1 scores than both Beginning $(\mathrm{M}=0.17, \mathrm{SE}=0.01)$ and Advanced $(\mathrm{M}=0.14, \mathrm{SE}=$ $0.01)$ dogs.

For all models, effect sizes remained in the very small range (all effect sizes less than 0.08 , with adjusted $R^{2}$ for all models below 0.10). That is, Age, Training Status and Breed Group together accounted for a small amount of variance in IA, HY1, and HY2 subscales. 


\section{Discussion}

In this study, we used a version of the ADHD Rating Scale [47] modified for dog owners to complete about their dogs' behaviours [40]. We collected Internet survey responses from a predominantly North American sample of dog owners. Our findings confirmed and expanded those of Vas et al. [40]. In our survey, owner reports of attention, activity, and impulsivity in dogs were unaffected by Gender when controlling for Age in adjusted models. In all models, the variables Age, Breed Group, and Training Status accounted for very little variance.

Our findings also confirmed that data collected with an Internet survey generated consistent findings when compared to researcher-assisted data collection, supporting web-based surveys as a means to generate valid data [60]. The attention subscale was particularly robust both in our data set and in Vas et al. [40]. Although two a priori subscales (IA and HA-IM) were previously identified [40], we identified a third subscale using factor analysis, suggesting that the HA-IM subscale might consist of two separable subscales. Indeed, HY2 was unaffected by Training Status, while both IA and HY1 showed effects of Training Status, with advanced training generating lower IA and HY1, but not lower HY2 subscale scores. Therefore this additional subscale might offer a valuable alternative endophenotype for subsequent investigations into genetic networks underlying attention, hyperactivity and impulsivity.

Consistent with Vas et al. [40], our complete model did not indicate any effect of physical size on IA, as the Toy group was not significantly different than other breed groups for any IA. However, we did find that the Herding group had significantly higher mean HY2 subscale scores than the Toy group. This differed from previous findings, and may demonstrate a difference identified by the presence of the additional subscale. The lack of effect of Gender on any subscale in dogs when effects of Age were controlled was consistent with previous findings [40,61].

We did find that some differences identified in univariate models were no longer present in adjusted models. This suggests that although the interactions between Breed Group and Training Status were not significant, they each accounted for sufficient variation in the other that the models including both variables were able to refine results. Even then, effect sizes remained extremely small. Differences in raw means (Table 4) were small, suggesting that statistically significant differences were due primarily to our large sample, and there are factors other than breed group, group, training, gender and age that account for variation in attention, activity and impulsivity. These factors may be environmental factors not captured by training history, such as living environment of the dog (outside vs. inside), amount of time dogs spend with their owners and activities other than training during that time or number of dogs in each household. It is also possible that variance can be explained by genetic background of dogs, but that comparing breed groups does not provide sufficient resolution to identify genetic variation that might be better identified through individual breed comparisons or across individuals within a single breed $[38,39]$. Moreover, assignment of training status according to certification or title received might result in some highly trained yet uncertified dogs included in the "untrained" category.

\section{Limitations}

One limitation of this study is the need to confirm whether additional variance can be explained by environmental or genetic factors. In addition, usefulness of the third scale identified within this study is unclear, and future experiments will be required to clarify this. Importantly, behavioural and physiological measures that correlate with survey reports are needed to establish validity of owner perceptions when evaluating behaviours in their dogs. This study also illustrated that although large samples may be obtained through use of Internet survey data collection methods, incomplete data may substantially impact final sample sizes.

One objection to utilizing dogs as a model for social cognition and cognitive disorders has been the suspicion that anthropomorphism underlies interpretation of findings $[42,62]$. It is possible that this questionnaire is simply measuring human bias in reporting and perception; that is, the same questions will yield the same structure of responses, regardless of population. This is a problem reflected in any psychological survey measure used in humans, and underscores the need to develop understanding of biological bases of both normal and pathological behaviours, potentially through the use of novel animal models.

Alternatively, it might be argued that the modifications made to the questionnaire in this study compared with Vas et al. [40] affect whether we have really tested the generalizability of the previous work in a new population or simply examined a variant of it. However, the congruence of our findings in a predominantly North American population of dog owners with those in an eastern European population [40], particularly given the questionnaire modifications, confirm that response structure appears consistent across populations, irrespective of data collection mechanism, breeds, and training beliefs and practices. 


\section{Conclusions}

These findings confirm reliability of this questionnaire as a tool for capturing owner observations of variability in attention, activity levels, and impulsivity in dog populations, and demonstrate that owner report provides dog scores according to "inattention" and "hyperactivityimpulsivity" axes. Validation of the dog as an animal model for ADHD will require in-depth characterization of behavioural and biological measures, both within and across breeds. It will be necessary to confirm whether a group of dogs can be identified displaying impulsivity that develops over time, inattention with temporally widely-spaced stimuli, hyperactivity in a non-novel environment that develops over time, altered reinforcement of novel behaviour and deficient extinction of previously reinforced behaviour. Further validation might identify breeds or lines with breeds that are more representative of distinct subtypes of ADHD, as shown by SHR substrains $[19,63]$. It is also important to identify whether dogs with extreme scores on any subscale demonstrate behavioural pathology as well as how well owner report (like parent report) accurately reflects behaviour; however, those questions are beyond the scope of this study. Findings of our study suggest that information provided by this behaviour scale can reliably provide an important basis for considering the genetic underpinnings of and environmental contributors to these behaviours in a dog model. Overall, this consistency supports use of a modified human measurement tool to evaluate attention, activity and impulsivity in dogs based on owner report.

Additional file 1: Survey questions. Questions derived from the ADHD Rating Scale [47] and Vas et al. [40], modified for American dog owners. Click here for file

[http://www.biomedcentral.com/content/supplementary/1744-9081-6-1S1.PDF ]

Additional file 2: Breed frequencies. Frequencies of owner-reported breeds included in the study.

Click here for file

[http://www.biomedcentral.com/content/supplementary/1744-9081-6-1S2.PDF ]

Additional file 3: Subscales. Questions derived from the ADHD Rating Scale [47] and Vas et al. [40], modified for American dog owners, and divided according to subscale identified in this study.

Click here for file

[http://www.biomedcentral.com/content/supplementary/1744-9081-6-1S3.PDF ]

\section{Acknowledgements}

This work was supported by an Autism Researcher Training Program fellowship (LL, T32 MH073124) and a private contribution. We appreciate the editorial and reviewer comments provided for this manuscript. In addition, we are grateful to all the dog owners who took time to fill out the survey.

\section{Author details}

'MIND Institute and Department of Neurology, University of California at Davis, Sacramento, CA, USA. ${ }^{2}$ Department of Psychiatry and Behavioral Science, University of California at Davis, Sacramento, CA, USA. ${ }^{3}$ Department of Public Health Sciences, Division of Biostatistics, University of California at Davis, Davis, CA, USA. ${ }^{4}$ Department of Animal Science, University of California at Davis, Davis, CA, USA.

\section{Authors' contributions}

LL conceptualized this study, designed the survey, conducted primary data analyses, and drafted the manuscript. JBS contributed to survey design, aided in data analyses and interpretation and assisted with manuscript preparation. AMI supervised data analyses and assisted with manuscript preparation. AMO contributed to survey design, assisted with data analyses and manuscript preparation. All authors have given approval of the final manuscript.

\section{Competing interests}

The authors declare that they have no competing interests.

Received: 1 September 2009

Accepted: 4 January 2010 Published: 4 January 2010

\section{References}

1. A.P.A.: Diagnostic and statistical manual of mental disorders: DSM-IV-TR Washington, DC: American Psychiatric Association, 42000.

2. Kessler RC, Adler L, Barkley R, Biederman J, Conners CK, Demler O, Faraone SV, Greenhill LL, Howes MJ, Secnik K, Spencer T, Ustun TB, Walters EE, Zaslavsky AM: The prevalence and correlates of adult ADHD in the United States: results from the National Comorbidity Survey Replication. Am J Psychiatry 2006, 163:716-723.

3. Barkley RA, Murphy KR, Fischer M: ADHD in Adults New York: Guilford Press 2007.

4. Lesch KP, Timmesfeld N, Renner TJ, Halperin R, Roser C, Nguyen TT, Craig DW, Romanos J, Heine M, Meyer J, Freitag C, Warnke A, Romanos M, Schafer H, Walitza S, Reif A, Stephan DA, Jacob C: Molecular genetics of adult ADHD: converging evidence from genome-wide association and extended pedigree linkage studies. J Neural Transm 2008, 115:1573-85.

5. Elia J, Devoto M: ADHD genetics: 2007 update. Curr Psychiatry Rep 2007, 9:434-439

6. Wallis $D$, Russell HF, Muenke M: Genetics of attention deficit/hyperactivity disorder. J Pediatr Psychol 2008, 33:1085-99.

7. Sagvolden T, Russell VA, Aase H, Johansen EB, Farshbaf M: Rodent models of attention-deficit/hyperactivity disorder. Biol Psychiatry 2005, 57:12391247.

8. Schneider JS, Sun ZQ, Roeltgen DP: Effects of dopamine agonists on delayed response performance in chronic low-dose MPTP-treated monkeys. Pharmacol Biochem Behav 1994, 48:235-240.

9. Roeltgen DP, Schneider JS: Task persistence and learning ability in normal and chronic low dose MPTP-treated monkeys. Behav Brain Res 1994, 60:115-124.

10. Roeltgen DP, Schneider JS: Chronic low-dose MPTP in nonhuman primates: a possible model for attention deficit disorder. I Child Neurol 1991, 6(Suppl):S82-89.

11. Russell VA, Sagvolden $T$, Johansen EB: Animal models of attention-deficit hyperactivity disorder. Behav Brain Funct 2005, 1:9.

12. Sagvolden T: Behavioral validation of the spontaneously hypertensive rat (SHR) as an animal model of attention-deficit/hyperactivity disorder (AD/ HD). Neurosci Biobehav Rev 2000, 24:31-39.

13. Howells FM, Bindewald L, Russell VA: Cross-fostering does not alter the neurochemistry or behavior of spontaneously hypertensive rats. Behav Brain Funct 2009, 5:24.

14. Hunziker MH, Saldana RL, Neuringer A: Behavioral variability in SHR and WKY rats as a function of rearing environment and reinforcement contingency. J Exp Anal Behav 1996, 65:129-144.

15. Berger DF, Sagvolden T: Sex differences in operant discrimination behaviour in an animal model of attention-deficit hyperactivity disorder. Behav Brain Res 1998, 94:73-82.

16. Alsop B: Reprint of "Problems with spontaneously hypertensive rats (SHR) as a model of attention-deficit/hyperactivity disorder (AD/HD)". J Neurosci Methods 2007, 166:XV-XXI. 
17. Bull E, Reavill C, Hagan JJ, Overend P, Jones DNC: Evaluation of the spontaneously hypertensive rat as a model of attention deficit hyperactivity disorder: acquisition and performance of the DRL-60s test. Behav Brain Res 2000, 109:27-35.

18. Bergh van den FS, Bloemarts E, Chan JSW, Groenink L, Olivier B, Oosting RS: Spontaneously hypertensive rats do not predict symptoms of attentiondeficit hyperactivity disorder. Pharmacol Biochem Behav 2006, 83:380-390.

19. Sagvolden T, Dasbanerjee T, Zhang-James Y, Middleton F, Faraone S: Behavioral and genetic evidence for a novel animal model of attentiondeficit/hyperactivity disorder predominantly inattentive subtype. Behav Brain Funct 2008, 4:56.

20. Sagvolden T, Johansen EB, Woien G, Walaas SI, Storm-Mathisen J, Bergersen $L H$, Hvalby $O$, Jensen V, Aase $H$, Russell VA, Killeen PR, Dasbanerjee T, Middleton FA, Faraone SV: The spontaneously hypertensive rat model of $A D H D$-the importance of selecting the appropriate reference strain. Neuropharmacology 2009, 57:619-626.

21. Hess EJ, Rogan PK, Domoto M, Tinker DE, Ladda RL, Ramer JC: Absence of linkage of apparently single gene mediated ADHD with the human syntenic region of the mouse mutant coloboma. Am J Med Genet 1995, 60:573-579.

22. Raber J, Mehta PP, Kreifeldt M, Parsons LH, Weiss F, Bloom FE, Wilson MC: Coloboma hyperactive mutant mice exhibit regional and transmitterspecific deficits in neurotransmission. J Neurochem 1997, 68:176-186.

23. Steffensen SC, Wilson MC, Henriksen SJ: Coloboma contiguous gene deletion encompassing Snap alters hippocampal plasticity. Synapse 1996, 22:281-289.

24. Wilson MC: Coloboma mouse mutant as an animal model of hyperkinesis and attention deficit hyperactivity disorder. Neurosci Biobehav Rev 2000, 24:51-57.

25. Gainetdinov RR, Caron MG: An animal model of attention deficit hyperactivity disorder. Mol Med Today 2000, 6:43-44

26. Giros B, Jaber M, Jones SR, Wightman RM, Caron MG: Hyperlocomotion and indifference to cocaine and amphetamine in mice lacking the dopamine transporter. Nature 1996, 379:606-612.

27. Casolini P, Zuena AR, Cinque C, Matteucci P, Alema GS, Adriani W, Carpinelli G, Santoro F, Alleva E, Bosco P, Nicoletti F, Laviola G, Catalani A: Sub-neurotoxic neonatal anoxia induces subtle behavioural changes and specific abnormalities in brain group-I metabotropic glutamate receptors in rats. J Neurochem 2005, 95:137-145.

28. Decker MJ, Hue GE, Caudle WM, Miller GW, Keating GL, Rye DB: Episodic neonatal hypoxia evokes executive dysfunction and regionally specific alterations in markers of dopamine signaling. Neuroscience 2003, 117:417425

29. Dalley JW, Theobald DE, Pereira EA, Li PM, Robbins TW: Specific abnormalities in serotonin release in the prefrontal cortex of isolationreared rats measured during behavioural performance of a task assessing visuospatial attention and impulsivity. Psychopharmacology (Berl) 2002, 164:329-340.

30. Carpenter DO, Hussain RJ, Berger DF, Lombardo JP, Park HY: Electrophysiologic and behavioral effects of perinatal and acute exposure of rats to lead and polychlorinated biphenyls. Environ Health Perspect 2002, 110(Suppl 3):377-386.

31. Holene E, Nafstad I, Skaare JU, Sagvolden T: Behavioural hyperactivity in rats following postnatal exposure to sub-toxic doses of polychlorinated biphenyl congeners 153 and 126. Behav Brain Res 1998, 94:213-224.

32. DasBanerjee T, Middleton FA, Berger DF, Lombardo JP, Sagvolden T, Faraone SV: A comparison of molecular alterations in environmental and genetic rat models of ADHD: a pilot study. Am J Med Genet B Neuropsychiatr Genet 2008, 147B:1554-1563.

33. Spady TC, Ostrander EA: Canine behavioral genetics: pointing out the phenotypes and herding up the genes. Am J Hum Genet 2008, 82:10-18.

34. Karlsson EK, Lindblad-Toh K: Leader of the pack: gene mapping in dogs and other model organisms. Nat Rev Genet 2008, 9:713-725.

35. Overall KL: Natural animal models of human psychiatric conditions: assessment of mechanism and validity. Prog Neuropsychopharmacol Biol Psychiatry 2000, 24:727-776.

36. Helton WS: Animal expertise, conscious or not. Anim Cogn 2005, 8:67-74

37. Helton WS: Deliberate practice in dogs: a canine model of expertise. $J$ Gen Psychol 2007, 134:247-257.
38. Hejjas K, Vas J, Kubinyi E, Sasvari-Szekely M, Miklosi A, Ronai Z: Novel repeat polymorphisms of the dopaminergic neurotransmitter genes among dogs and wolves. Mamm Genome 2007, 18:871-879.

39. Hejjas K, Vas J, Topal J, Szantai E, Ronai Z, Szekely A, Kubinyi E, Horvath Z, Sasvari-Szekely M, Miklosi A: Association of polymorphisms in the dopamine D4 receptor gene and the activity-impulsivity endophenotype in dogs. Anim Genet 2007, 38:629-633.

40. Vas J, Topal J, Pech E, Miklosi A: Measuring attention deficit and activity in dogs: a new application and validation of a human ADHD questionnaire. Appl Anim Behav Sci 2007, 103:105-117.

41. Lindblad-Toh K, Wade CM, Mikkelsen TS, Karlsson EK, Jaffe DB, Kamal M, Clamp M, Chang JL, Kulbokas EJ, Zody MC, Mauceli E, Xie X, Breen M, Wayne RK, Ostrander EA, Ponting CP, Galibert F, Smith DR, deJong PJ, Kirkness E, Alvarez P, Biagi T, Brockman W, Butler J, Chin C-W, Cook A, Cuff J, Daly MJ, DeCaprio D, Gnerre S, Grabherr M, Kellis M, Kleber M, Bardeleben C, Goodstadt L, Heger A, Hitte C, Kim L, Koepfli K-P, Parker HG, Pollinger JP, Searle SMJ, Sutter NB, Thomas R, Webber C, Lander ES: Genome sequence, comparative analysis and haplotype structure of the domestic dog. Nature 2005, 438:803-819.

42. Miklosi A, Topal J, Csanyi V: Big thoughts in small brains? Dogs as a model for understanding human social cognition. Neuroreport 2007, 18:467-471.

43. Brauer J, Kaminski J, Riedel J, Call J, Tomasello M: Making inferences about the location of hidden food: social dog, causal ape. J Comp Psychol 2006, 120:38-47

44. Hare B, Brown M, Williamson C, Tomasello M: The domestication of social cognition in dogs. Science 2002, 298:1634-1636.

45. Seksel K, Lindeman MJ: Use of clomipramine in treatment of obsessivecompulsive disorder, separation anxiety and noise phobia in dogs: a preliminary, clinical study. Aust Vet J 2001, 79:252-256.

46. Topal J, Miklosi A, Csanyi V, Doka A: Attachment behavior in dogs (Canis familiaris): a new application of Ainsworth's (1969) Strange Situation test. J Comp Psychol 1998, 112:219-229.

47. DuPaul GJ: ADHD Rating Scale-IV: Checklist, Norms and Clinical Interpretations. New York: Guilford Press 1998.

48. Barnard-Brak L, To Y: Examining parental nonresponse to stimulant treatment questions according to ethnicity. J Child Adolesc Psychopharmacol 2009, 19:301-304.

49. Hillemeier MM, Foster EM, Heinrichs B, Heier B: Racial differences in parental reports of attention-deficit/hyperactivity disorder behaviors. $J$ Dev Behav Pediatr 2007, 28:353-361.

50. Staay van der FJ: Animal models of behavioral dysfunctions: basic concepts and classifications, and an evaluation strategy. Brain Res Rev 2006, 52:131-159.

51. Staay van der FJ, Arndt SS, Nordquist RE: Evaluation of animal models of neurobehavioral disorders. Behav Brain Funct 2009, 5:11.

52. Johnson KA, Wiersema JR, Kuntsi J: What would Karl Popper say? Are current psychological theories of ADHD falsifiable? Behav Brain Funct 5:15. Behav Brain Funct 2009, 5:15.

53. Survey Monkey. http://www.surveymonkey.com.

54. Cronbach LI, Meehl PE: Construct validity in psychological tests. Psychol Bull 1955, 52:281-302.

55. Cronbach L: Coefficient alpha and the internal structure of tests. Psychometrika 1951, 16:297-334.

56. SPSS. http://www.spss.com

57. Cortina JM: What is coefficient alpha - an examination of theory and applications. J Appl Psychol 1993, 78:98-104.

58. Guttman L: Some necessary conditions for common-factor analysis. Psychometrika 1954, 19:149-161.

59. Kaiser HF: A note on Guttman lower bound for the number of common factors. Br J Math Stat Psychol 1961, 14:1-2.

60. Gosling SD, Vazire S, Srivastava S, John OP: Should we trust web-based studies? A comparative analysis of six preconceptions about internet questionnaires. Am Psychol 2004, 59:93-104.

61. Neilson JC, Hart BL, Cliff KD, Ruehl WW: Prevalence of behavioral changes associated with age-related cognitive impairment in dogs. J Am Vet Med Assoc 2001, 218:1787-1791.

62. Horowitz AC, Bekoff M: Naturalizing anthropomorphism: behavioral prompts to our humanizing of animals. Anthrozoos 2007, 20:23-35. 
63. Sagvolden T, Johansen EB, Wøien G, Walaas SI, Storm-Mathisen J, Bergersen LH, Hvalby $\varnothing$, Jensen V, Aase $H$, Russell VA, Killeen PR, DasBanerjee T, Middleton FA, Faraone SV: The spontaneously hypertensive rat model of ADHD - The importance of selecting the appropriate reference strain. Neuropharmacology 2009, 57:619-626.

doi:10.1186/1744-9081-6-1

Cite this article as: Lit et al:: Owner reports of attention, activity, and impulsivity in dogs: a replication study. Behavioral and Brain Functions 2010 6:1

Publish with Biomed Central and every scientist can read your work free of charge

"BioMed Central will be the most significant development for disseminating the results of biomedical research in our lifetime. " Sir Paul Nurse, Cancer Research UK

Your research papers will be:

- available free of charge to the entire biomedical community

- peer reviewed and published immediately upon acceptance

- cited in PubMed and archived on PubMed Central

- yours - you keep the copyright 